TAO, Supplementary Issue, 231-248, May 2001

\title{
Crustal Structure at the Intersection of the Ryukyu Trench with the Arc-Continent Collision in Taiwan: Results from an Offshore-Onshore Seismic Experiment
}

\author{
Eric A. Hetland ${ }^{1,2, *}$ and Francis T. Wu ${ }^{1}$ \\ (Manuscript received 1 July 2000, in final form 5 February 2001)
}

\begin{abstract}
The ongoing orogeny in Taiwan is a result of the collision of the Philippine Sea and the Eurasian Plates. While the structure of the continental crust on the Eurasian Plate (EP) is now mostly known, that of the oceanic crust on the Philippine Sea Plate (PSP) has never been well mapped. Using offshore-onshore refraction data, collected during the $\mathrm{R} / \mathrm{V}$ Maurice Ewing cruise of 1995, the nature of the transition between the EP and the PSP at the Ryukyu Trench and the Longitudinal Valley, Taiwan was investigated. The data were produced by the air-gun array of the $\mathrm{R} / \mathrm{V}$ Ewing along two roughly east-west trending lines off the coast of northern Taiwan (R/V Ewing Lines 14 and 16). The refracted $P$ waves were collected by 19 RefTek recorders with L-28 sensors placed along the Central Cross-Island Highway of Taiwan, which is the onshore extension of Ewing Line 16. Because of high noise levels in the Coastal Plain and equipment failure at stations near the east coast, only data retrieved from nine stations in the Central Range were considered usable. To obtain crustal structure, an inversion and forward modelling scheme was followed and the results indicate that the Moho discontinuity gradually increases depth from about $30 \mathrm{~km}$ below sea level under the Nanao Basin to about $37 \mathrm{~km}$ below sea level under the Eastern Central Range. Additionally, the model of the northern profile contains a relatively low velocity zone off the east coast, possibly as deep as the lowerto-middle crust.
\end{abstract}

(Key words: Offshore-onshore seismic refraction, Arc-continent collision, Orogeny, Travel-time inversion)

\footnotetext{
${ }^{1}$ Department of Geological Sciences, State University of New York at Binghamton, Binghamton, NY 13902, USA

${ }^{2}$ Now at Department of Earth, Atmospheric and Planetary Science, Massachusetts Institute of Technology, Cambridge, MA, 02139, USA.

* Corresponding author address: Eric A. Hetland, 54-610, Massachusetts Institute of Technology, 77 Massachusetts Ave., Cambridge, MA 02139, USA; E-mail: eah@mit.edu
} 


\section{INTRODUCTION}

The Taiwan orogeny is a result of the arc-continent collision between the Luzon volcanic arc on the Philippine Sea Plate (PSP) and the Chinese continental margin on the Eurasian Plate (EP). The main arc-continent collision is ongoing between about $22 \mathrm{~N}$ and $23.5 \mathrm{~N}$ at the Longitudinal Valley (Wu et al.1997), which is the recognized contact between the EP and the PSP (Chai 1972; Biq 1972; Bowin et al. 1978; Wu 1978; Angelier et al. 1986; Barrier and Angelier 1986; Ho 1986; Huchon et al. 1986). GPS results show that west of the Longitudinal Valley there is rapid deformation, while north of about $24 \mathrm{~N}$ there is little deformation (Yu et al. 1997). The lack of current surface deformation in the northern part of the orogen implies that this region is either no longer affected by the collision or that it is deforming at depth only. Northeast of Taiwan, the PSP is subducting to the northwest under the EP (Katsumata and Sykes 1969; and others). Based on tomographic and seismicity studies, the terminus of the PSP subduction was determined to be near the east coast of Taiwan at $23.8 \mathrm{~N}, 121.5 \mathrm{~N}$ (Wu et al. 1997), which is slightly northwest of the Coastal Range.

Offshore Taiwan, between the island, the Hsincheng Ridge and the Ryukyu Arc there is a deep depression, the Hoping Basin (Fig. 1). Farther east off the coast of Taiwan, between the Ryukyu Arc and the Yaeyama Ridge, are the Nanao and East Nanao Basins. All three of these basins coincide with a deep Bouguer anomaly low (up to -160 mgals), which extends more than $200 \mathrm{~km}$ from the east coast (Hsu et al. 1998). However, over the Hoping basin, the gravity anomaly is longer in the north-south direction and is significantly lower (almost $100 \mathrm{mgal}$ lower) than the average anomaly over the accretionary prism in the east (Hsu et al. 1998).

The marine-based data collected offshore northeast Taiwan during the 1995 R/V Ewing cruise (EW9509) can be used to examine the area around the Ryukyu Trench. During the cruise, multi-channel seismic (MCS) lines were shot by a 20-element air-gun array. The air-gun shots were recorded both by ocean bottom seismometers (OBS) deployed along Lines 14 and 16 and by onshore seismometers. The MCS data could resolve the sedimentary layers of the uppermost crust and those in the trench. The OBS, on the other hand, were able to record waves penetrating the lower-crust, and therefore, determined the deep crustal structures. The geometry of the OBS transect yielded dense ray coverage and split profiles, which could be modelled with good resolution. However, since the profiles stopped short of the Taiwan coast, they did not cover the plate transition zone where changes in crustal structure are likely to be the most pronounced. However, the onshore stations recorded waves crossing this transition. Preliminary analysis of these data show that their quality allowed for the resolution of several important features of the crust (Hetland and Wu 1998a; Shih et al. 1998; Yeh et al. 1998).

This paper presents a detailed analysis of the two northern offshore-onshore lines (Lines 16 and 14), which shared the same onshore recorder deployment and were sub-parallel offshore, mending WNW-ESE (Fig. 1). The following sections describe the R/V Ewing cruise and present the methods, results, analysis and conclusions of this study. 


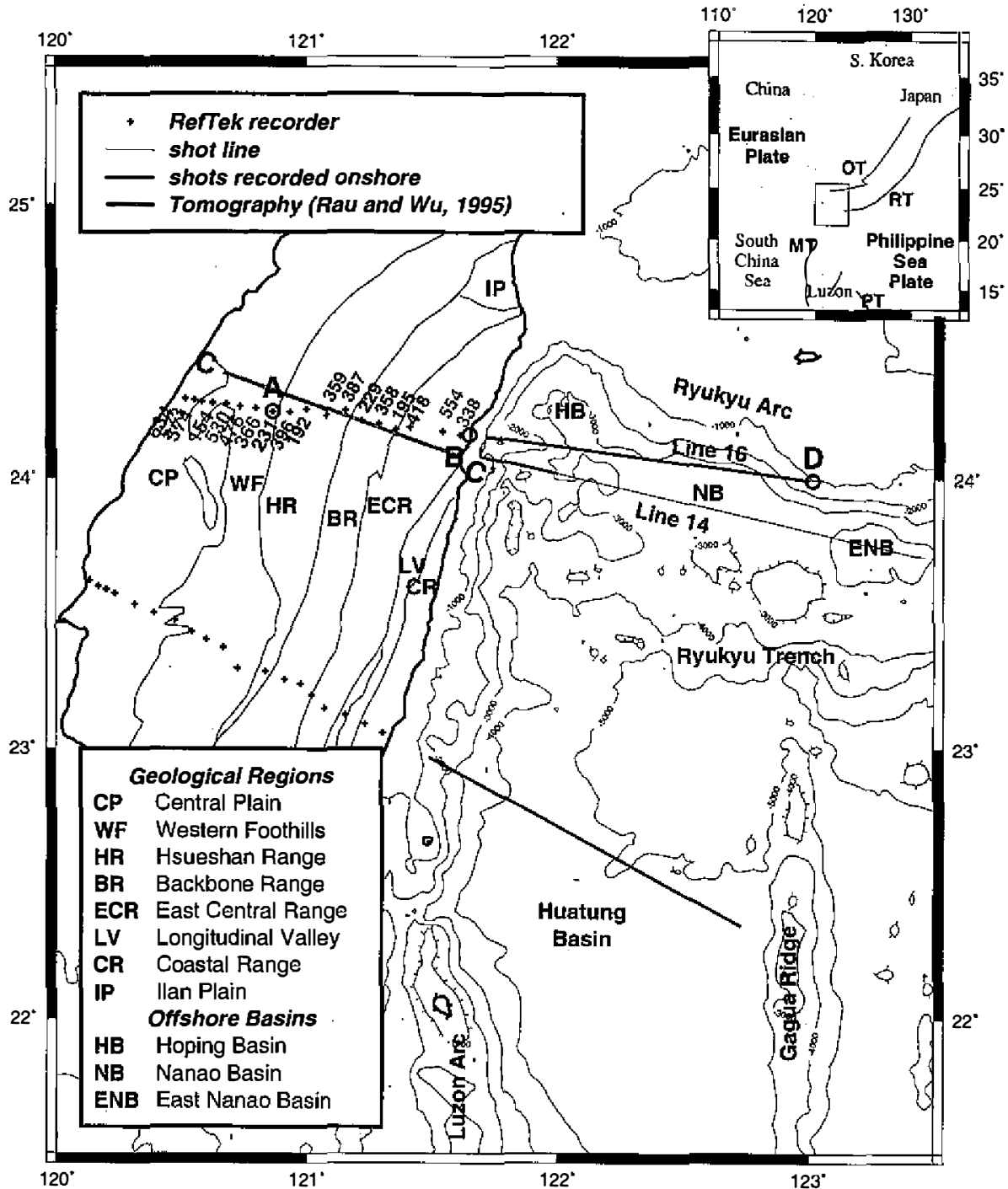

Fig. I. Locations of transects offshore and onshore Taiwan. Bathymetry is contoured every 1,000 meters and general geological regions are indicated. Only the northern profile is presented in this paper. All stations deployed on the onshore extension of Line 16 are labeled with their RefTek serial numbers, and stations with data used in this study are indicated in solid black. The circles refer to end-points of the cross-sections presented in this study, and profile C-C' is a tomographic profile determined by Rau and $\mathrm{Wu}$ (1995). Inset map shows the surrounding tectonic features: MT is the Manila Trench, PT is the Philippine Trench, OT is the Okinawa Trough and RT is the Ryukyu Trench. 


\section{OFFSHORE-ONSHORE EXPERIMENT}

During the $1995 \mathrm{R} / \mathrm{V}$ Maurice Ewing cruise, an offshore-onshore experiment, consisting of three profiles composed of five offshore MCS/OBS lines, was conducted. The first offshore-onshore profile trended E-W across the Hengchun Peninsula (Yeh et al. 1998), and the second trended ENE-WSW across the Central Range, Longitudinal Valley and the Coastal Range in the main collision zone (Hetland and Wu 1998b; Yeh et al. 1998). The third, northernmost offshore-onshore profile (Fig. 1), is presented and analyzed in this paper. Onshore, the northern profile is along the extension of Ewing Line 16, roughly along the Central Cross-Island Highway, which crosses the Western Foothills and the Hsueshan, Backbone and East Central Ranges. Offshore, the northern profile is along Line 16, which runs over the Hsinchen Ridge, cutting across the Hoping Basin and along the northern part of the Nanao Basin and finally approaches the Ryukyu Arc (Figs. 1 and 2). In this profile, we also include Ewing Line 14, which is south and sub-parallel to Line 16 and runs between the Ryukyu Trench and Ryukyu Arc, starting south of the Hsinchen Ridge and continuing eastward over the Nanao and East Nanao Basins (Fig. 1). Although, only a small sub-set of the shots along Line 14 were recorded onshore, those were quite close to the island. Hence, only upper-crust arrivals were recorded from Line 14, and these were used to constrain the upper-crust velocities along the profile.

Along Line 14, the 20-element air-gun array ( 8470 cubic inches per element) was fired every 20 seconds, while the R/V Ewing steamed westward at a velocity such that the shots were spaced nominally every $25 \mathrm{~m}$. Along Line 16 , the frequency was decreased to every 40 seconds, while the vessel steamed eastward, making the shot points nominally spaced every $100 \mathrm{~m}$. Due to operational difficulties, the northern stations did not start recording data from Line 14 until the R/V Ewing was close to the island (about $40 \mathrm{~km}$ ). Altogether, 35 stations were established onshore along the northern profile, and these included 18 RefTek recorders with L-28 sensors (PASSCAL 1994). Fifteen of these recorders were borrowed from IRIS/ PASSCAL by SUNY Binghamton, while the other three were provided by the Institute of Earth Sciences, Academia Sinica, Taiwan. Here, we analyze the data collected from the RefTek recorders; a description of the data recorded by the remaining recorders is found in Yeh et al. (1998).

\section{OFFSHORE-ONSHORE DATA}

In this study, we concentrated primarily on the earliest $\mathrm{P}$ waves detected by the onshore recorders. Since, in a complex structure, out-of-plane reflections and refractions, multiples and converted waves all interfere with the identification and picking of later arrivals. The picking of the arrivals on the section plots is straightforward. We picked the first arrival times on common receiver gathers (CRG). Based on source and receiver reciprocity (Lay and Wallace 1995), the CRG are east-looking profiles (i.e., equivalent to a profile with source fixed at the receiver site with stations with larger offset toward the east), whereas common shot gathers (CSG) are west-looking profiles. In this paper we present the CRG of Line 16 from stations 396 and 229 (we use the serial numbers of the RefTek recorders to denote the stations; Fig. 3) 
along with a CRG of Line 14 from station 418 (Fig. 4).

The signals recorded by the stations onshore were quite clear for offsets up to about 180 $\mathrm{km}$ (Fig. 3). The signal-to-noise ratios were generally enhanced when filtered with a two-pass, Butterworth band-pass filter (Oppenheim and Schafer 1989), which was part of the SU software package used here (Cohen and Stockwell 1999). The filtering caused small arrival precursors in the data and these were taken into account when picking arrival times. We used a filter with corner frequencies of 5 and $7 \mathrm{~Hz}$ and a raise of $2 \mathrm{~Hz}$ for all of the data. After filtering, to enhance the resolution of the sections, we muted all time windows with high noise

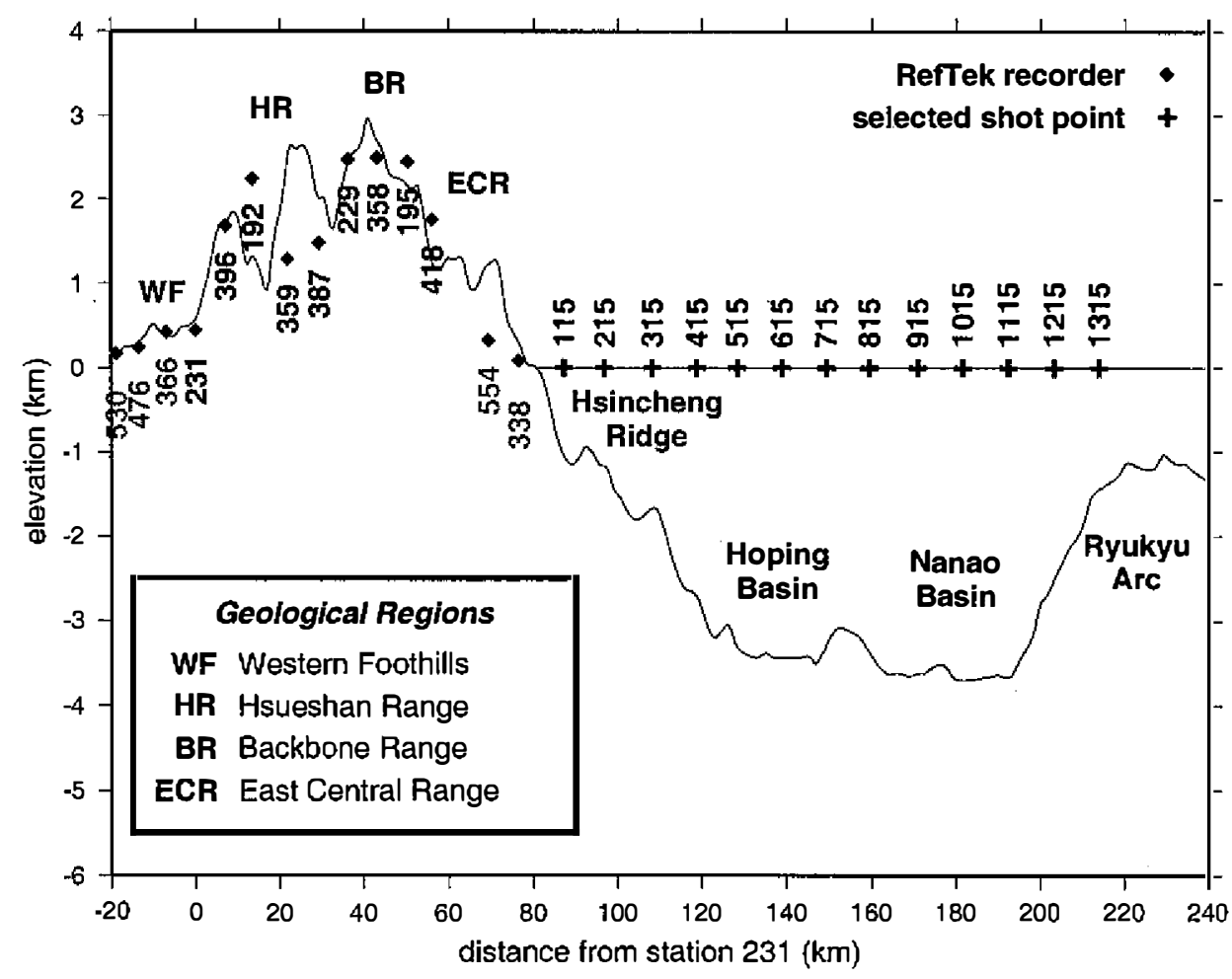

Fig. 2. Profile of offshore-onshore Line 16. Locations of onshore stations (diamonds) are plotted with their elevation along the onshore extension of Ewing Line 16. The stations are labeled with their RefTek serial numbers. Some stations are above or below the elevation profile since they were located slightly off the onshore extension of Ewing Line 16 (Fig. 1). We used the stations' actual elevations for all of the travel-time calculations in this study; therefore, no correction due to the deviation in placement of the stations was required. The locations of every hundredth shot point (crosses) are plotted above the bathymetry under Ewing Line 16; shots 115-1315 along Line 16 were recorded onshore. (Vertical exaggeration is 20 ) 
a)

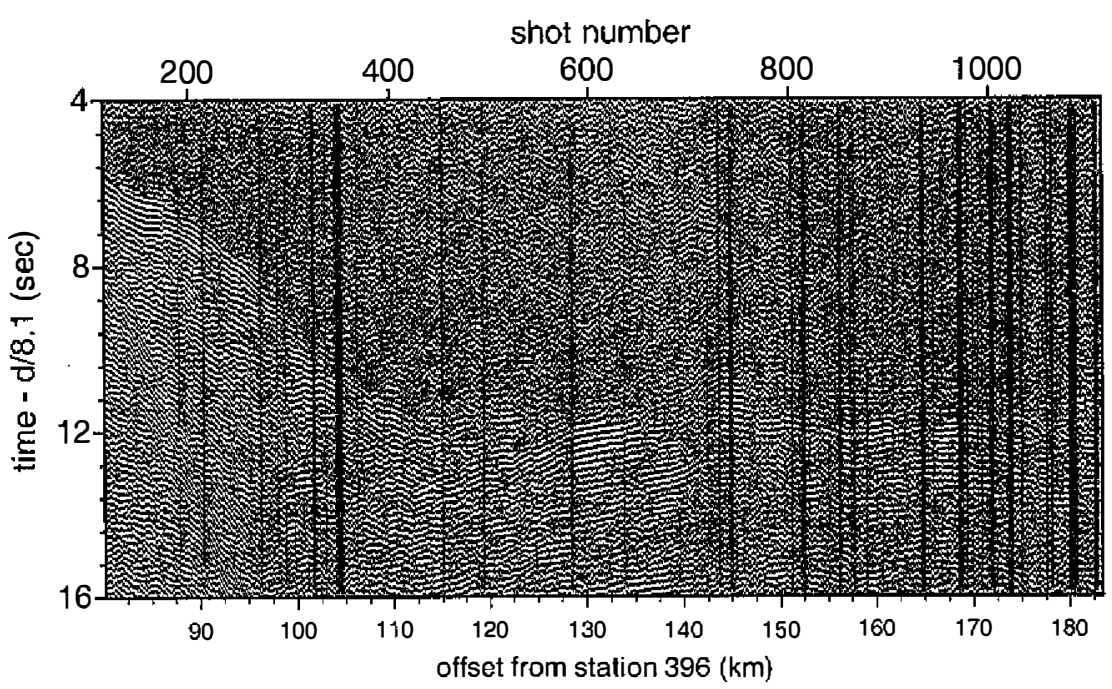

b)

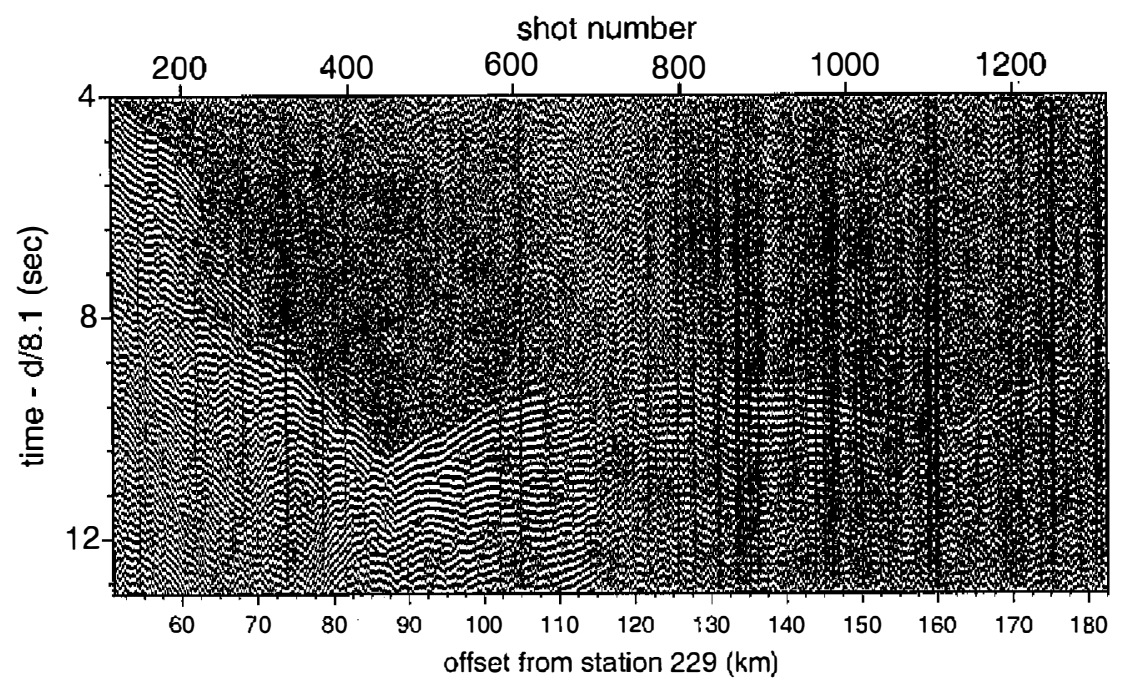

Fig. 3. Common receiver gathers of vertical component data from Ewing Line 16 recorded by two stations, (a) 396 and (b) 229. Data were pre-processed as explained in section 3 , and time was reduced at $8.1 \mathrm{~km} / \mathrm{sec}$. (See Fig. 2 for the location of the shots.)

levels which obscured the arrival signals. For stations in the Hsueshan Range, the signals were not very obvious on individual traces, but when plotted as a section, the waves could be readily traced. For stations in the Coastal Plain and Western Foothills, however, the noise levels were usually quite high, and no arrivals could be discerned, which seemingly can be attributed to 


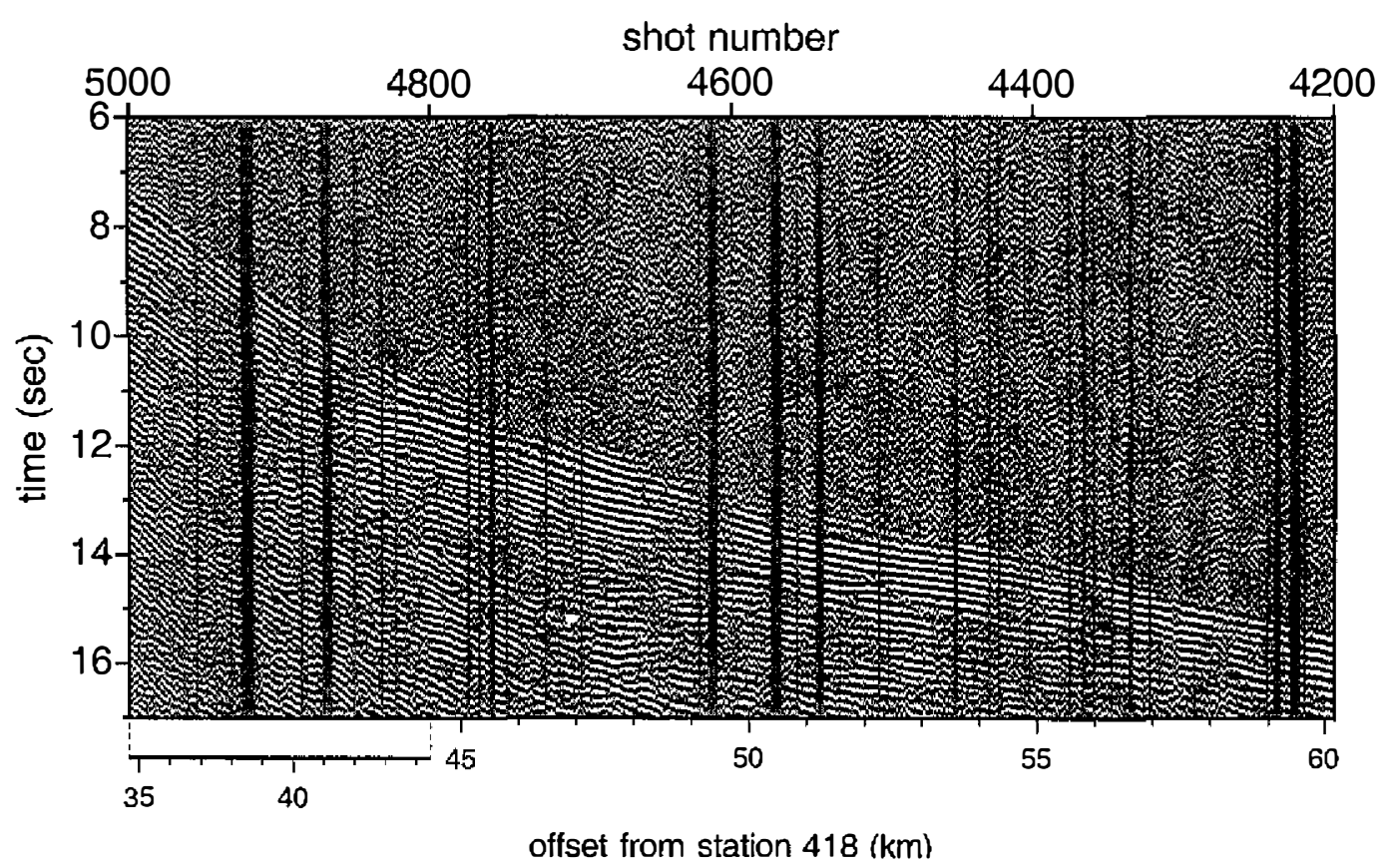

Fig. 4. Common receiver gather of vertical component data from Ewing Line 14 recorded at station 418 , located in the Eastern Central Range. Data were pre-processed as explained in section 3 , and time was not reduced. Note that shots 4800-5000 have a different offset scale than shots $4200-4800$ due to the change in trend of Line 14 (see Fig. 1). (See Fig. 2 for the location of the shots.)

cultural noise in these regions. For example, at station 366 in the Western Foothills, the noise level was generally higher than the signals at neighboring station 231 in the Hsueshan Range. Apart from this, no data could be used from the two easternmost stations. At station 338, closest to the east coast, none was recorded due to equipment failure, while at the adjacent station (554), an unexplained timing error made the data to be unuseable.

Only the shots closest to Taiwan along Ewing Line 14 were recorded onshore. The apparent velocity of these arrivals was $3.8+/-0.8 \mathrm{~km} / \mathrm{sec}$ on both the CRG and CSG sections, and we identified these arrivals as $\mathrm{P}$ waves refracted in the upper-crust $(\mathrm{Pg})$.

Most of the first arrivals from shots along Ewing Line 16 could be classified into two groups based on their apparent velocities $\left(\mathrm{v}_{\mathrm{a}}\right)$. For the first refracted arrivals, the $\mathrm{v}_{\mathrm{a}}$ at all stations was about $4.0+1-0.5 \mathrm{~km} / \mathrm{sec}$, and we determined that these were $P$ waves refracted in the upper-crust $(\mathrm{Pg})$. The second refracted group had a high $\mathrm{v}_{\mathrm{a}}$ (over $9 \mathrm{~km} / \mathrm{sec}$ ) at small offsets and a lower $v_{a}$ (about $6 \mathrm{~km} / \mathrm{sec}$, a mid-crust velocity) at larger offsets (Fig. 5). These arrivals were determined to be waves refracted in the lower-crust ( $\mathrm{Pc}$ ), while a strong, localized velocity discontinuity or gradient in the crust caused the wavefield of some arrivals to refract sharply resulting in a lower horizontal slowness, and hence, a higher $v_{a}$ (e.g., Lay and Wallace 1995). 


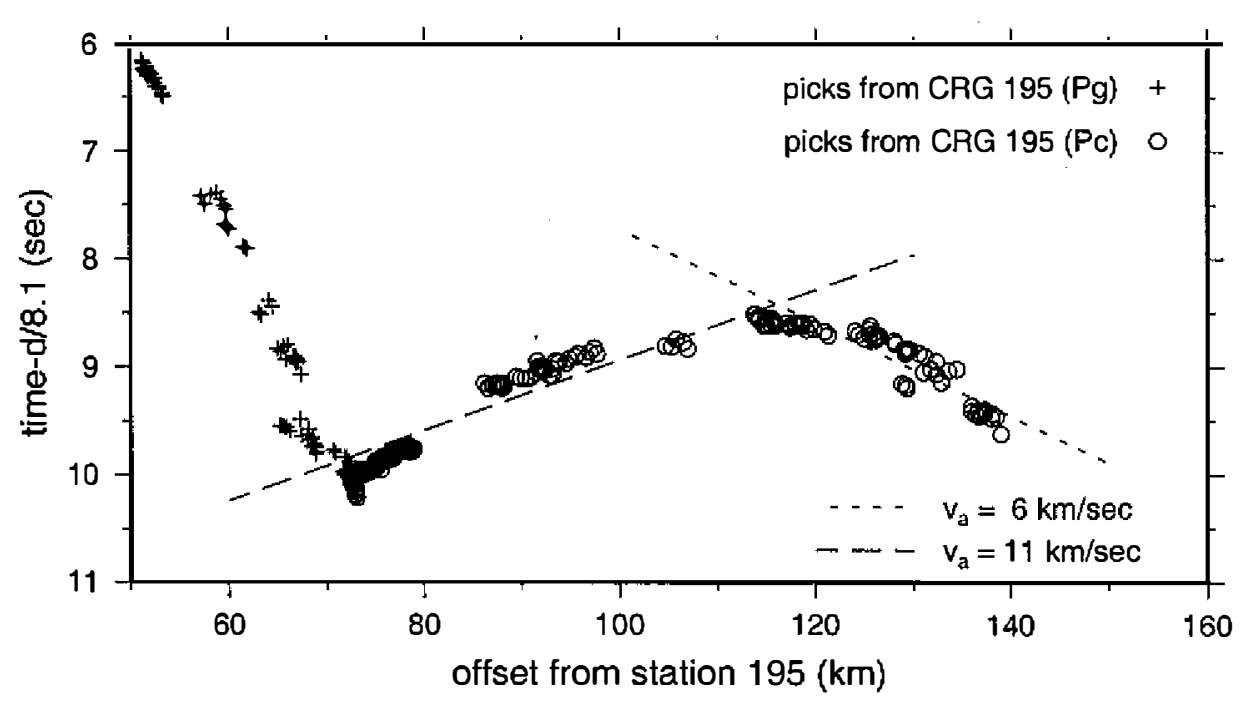

Fig. 5. Travel-time picks from common receiver gather 195. The near offset (about $85-110 \mathrm{~km}$ ) arrivals have a large apparent velocity, while those at larger offsets (about 110-140 km) have a lower apparent velocity. Two lines of constant apparent velocity $\left(\mathrm{V}_{\mathrm{a}}\right)$ and Pg travel-time picks are plotted for reference.

Additionally, on a few of the CRG sections refracted arrivals were found at large offsets, with $\mathrm{v}_{\mathrm{a}}$ greater than $8.1 \mathrm{~km} / \mathrm{sec}$. We identified these as critically refracted waves off the Moho (Pn) and as waves refracted in the mantle.

\section{ANALYSIS}

In this study, we initially attempted - albeit unsuccessfully - to model Pn arrivals with a simple two-layered model, with constant velocities, composed of a planar horizontal-to-west dipping Moho. We used a grid search approach to solve for the model parameters. Using this approach, model parameters are varied regularly over chosen parameter ranges, and traveltimes are computed for each iteration and compared to the observed times. Accordingly, with sufficiently large parameter ranges, it is normally possible to completely map out the solution space of the problem. In modelling a uni-directional, offshore-onshore profile, the grid search approach has been shown to be robust when all modelled arrivals can be treated as critically refracted in a layered structure with constant velocities in each layer (Hetland and Wu 1998). However, due to the structural complexity along this profile, this method was not capable of such modelling. Due to this failure, we then used an inversion and forward modelling.

\subsection{Travel-Time Inversion}

To solve for detailed crustal structure using an inversion and forward modelling scheme, 
we had to assume an initial crustal model which was complex enough to roughly describe the arrivals we identified in the CRG sections. For our initial model, we used the results of OBS Line 16 by Wang and Chiang (1998) for the oceanic structure, while for the continental crustal structure, we used the results of the tomographic study under the Taiwan orogen by Rau and $\mathrm{Wu}(1995)$. We inverted the travel-times using the ray-tracing and inversion software package Rayinvr2 (Zelt and Smith 1992).

After inversion, we checked the model with forward ray-tracing, always ensuring that three criteria were satisfied: first, that the model was reasonable; second, that the phases of the theoretical arrivals corresponded to the identified arrivals; and third, that all travel-time picks were modelled. We dismissed a model as unreasonable if boundaries crossed, if velocity discontinuities had an extremely high velocity change, or if there were large negative vertical velocity gradients. The second and third criteria were strongly coupled. For example, the third criterion was commonly violated if the inverted model had strong or negative velocity gradients that caused ray paths to focus or cross. If the model obtained from inversion violated any of the above three criteria, we isolated the cause of the violation and corrected it through trial-and-error forward modelling. We then continued in this fashion (inversion and forward modelling) and in the end we had several resulting models that were reasonable and described the data well. We obtained twelve models that could model the observed ravel-times sufficiently. Although, most of the models shared common features, in this paper we present the model that best described the observed data (Figs. 6 and 8). The rejection of the other resultant models in favor of the one presented was based, in part, on a slight increase in fit of some arrivals, namely the arrivals recorded at the eastern stations (Figs. $6 \mathrm{~b}$ and 10), with no-to-only a slight change in the fit of the other arrivals. The acceptance of one preferred model is open to bias; therefore, the presented model is discussed along with the other models in the Discussion section.

\subsection{Arrivals From Ewing Line 14}

We analyzed the arrivals from shots along Line 14 to further constrain the upper-crust velocity structure. Due to the differing locations and geometries of Lines 14 and 16 (Fig. 1), the Pg arrivals from Line 14 only approximate those from Line 16 . In order to model the arrivals from Line 14, we needed to make slight perturbations to the upper-crust velocities determined from the analysis of the arrivals from Line 16 alone. We decreased the velocity under station 231 by about $0.5 \mathrm{~km} / \mathrm{sec}$ and increased the velocity under stations 396 and 192 by about $0.5 \mathrm{~km} / \mathrm{sec}$. Figure 7 presents the results of the fit between the observed and calculated times for the final model (Fig. 6).

The fit of the arrivals from Line 14 recorded at the western stations (Fig. 7) is not optimum; however, there is a significant trade-off between the fit of the arrivals from Line 16 and Line 14 for those stations. For instance, the calculated times are slightly faster than the arrivals from Line 16 (Fig. 6b), whereas they are slower than the arrivals from Line 14 (Fig. 7). We chose to model the arrivals from Lines 14 and 16 recorded at the western stations simultaneously. Our inability to fit the data well is an indication of the lack of control we had over the velocities at the edges of the model and the impossibility to resolve more complex velocity gradients. 
a)

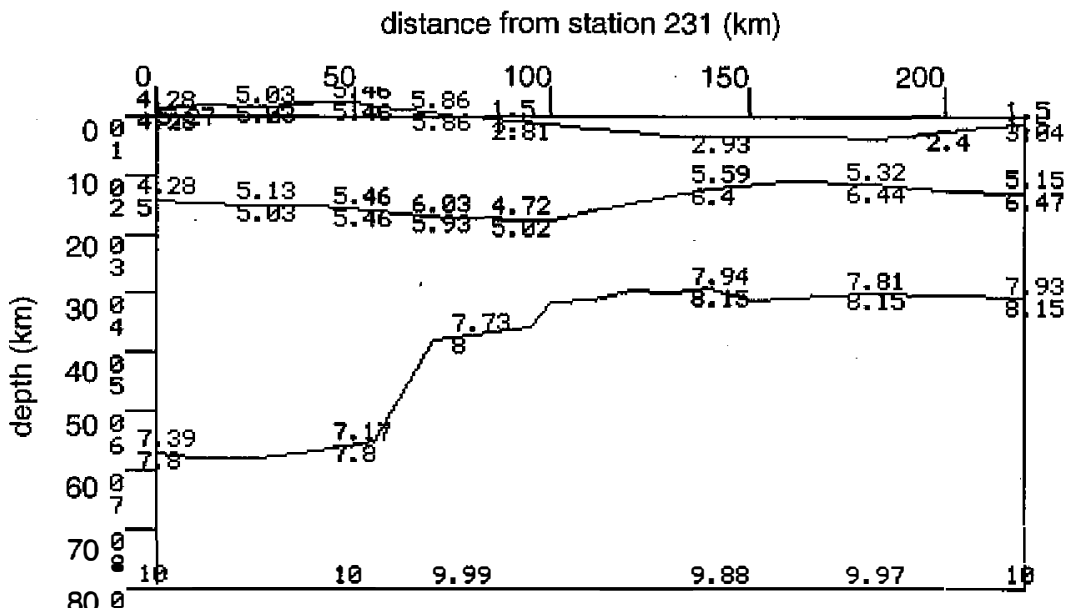

b)
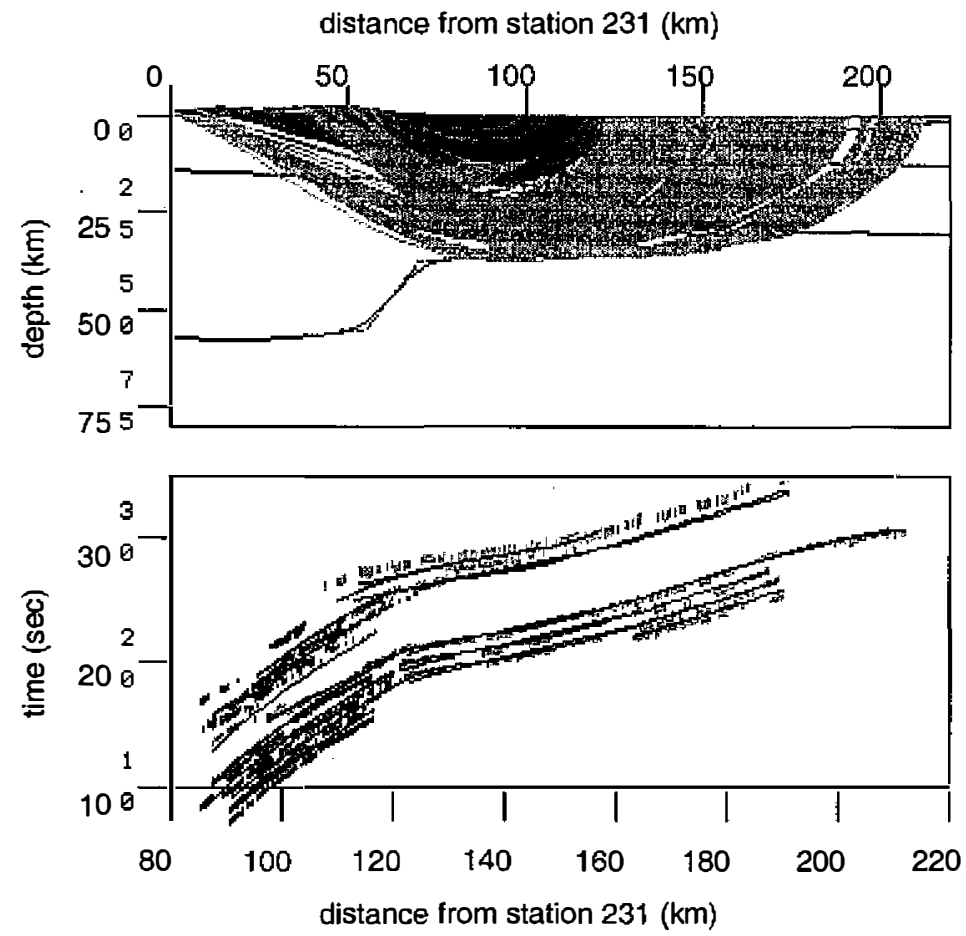

Fig. 6. a) Model obtained during an inversion and forward modelling scheme. Vertical exaggeration is 1.5. See Fig. 1 for locations of the cross-section end-points. b) Ray paths and calculated ravel-times (lines) compared to travel-time picks of the observed data (small vertical bars). Travel-time picks of arrivals recorded from Line 14 are included in the ray-tracing. 


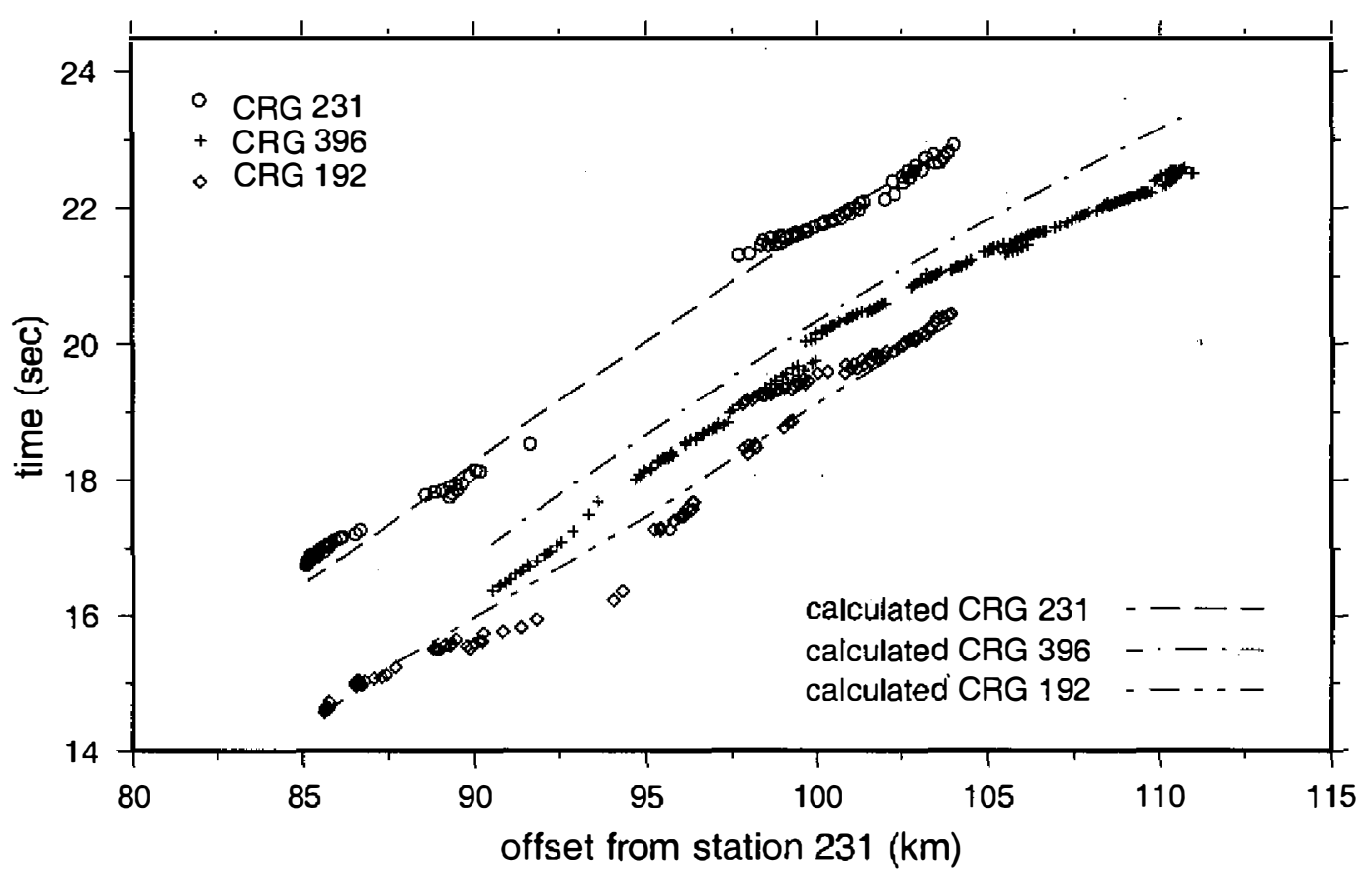

Fig. 7. Calculated travel-times (dashed lines) plotted with travel-time picks (symbols) of shots from Ewing Line 14 recorded at stations 231, 396 and 192. The arrivals are upper-crust refracted waves. The velocity model is presented in Fig. 6.

\section{DISCUSSION}

Figure 8a shows the preferred model of this study along with the standard deviations of the model parameters of all of the models that described the data sufficiently well (Fig. 8b). In this figure we also smoothed the velocity in order to bring out several features of the model. The standard deviations represent a quantitative description of the amount of scatter in the model parameters between the preferred model and all of the models that were discarded due to qualitative determinations. To select the preferred model, we favored the fit of the eastern stations over that of the western stations, the fit of the Pc, Pn and mantle arrivals over that of $\mathrm{Pg}$ and the fit of relatively clear arrivals over that of arrivals with low signal-to-noise ratios. Figure 10 shows an example of the final fit from one of the eastern stations.

In all final models, three main features of the upper-crust were common to all and could be determined by modelling Pg and small offset Pc arrivals. First, the velocity gradient under the Central Range was lower than that under the ocean (Fig. 9). Secondly, the average uppercrust velocity under Taiwan was higher than that under the ocean (an average of about $1 \mathrm{~km} /$ sec higher). Finally, in all models a low velocity zone in the upper-crust was resolved near the coast of Taiwan (Fig. 8).

Three main features of the lower-crust and Moho were resolved in all of the final models 
a)

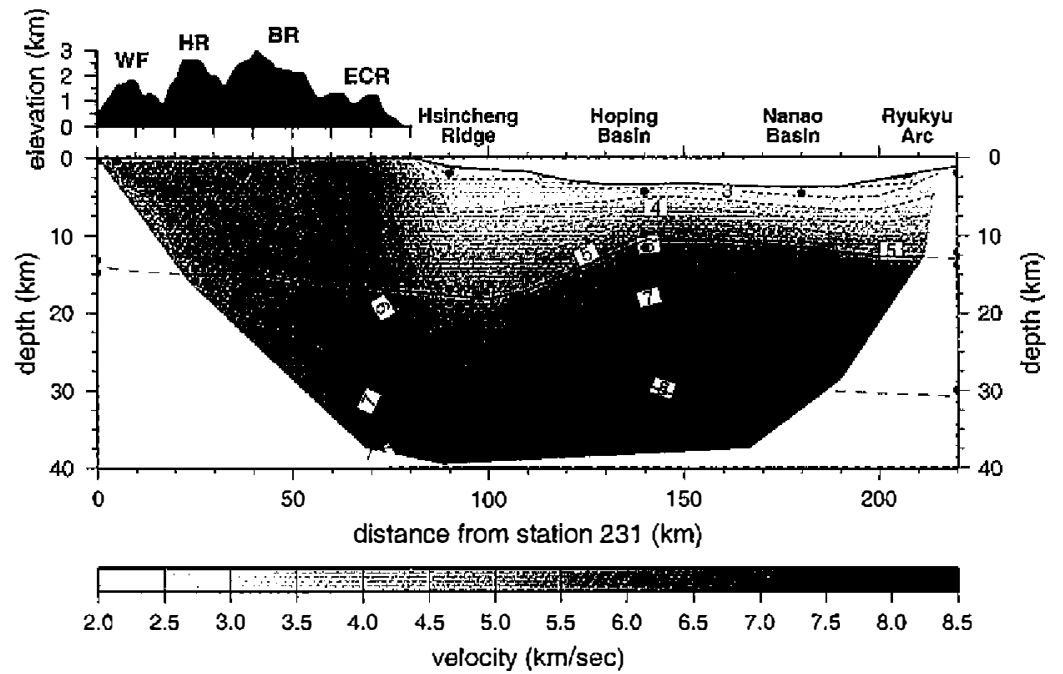

b)

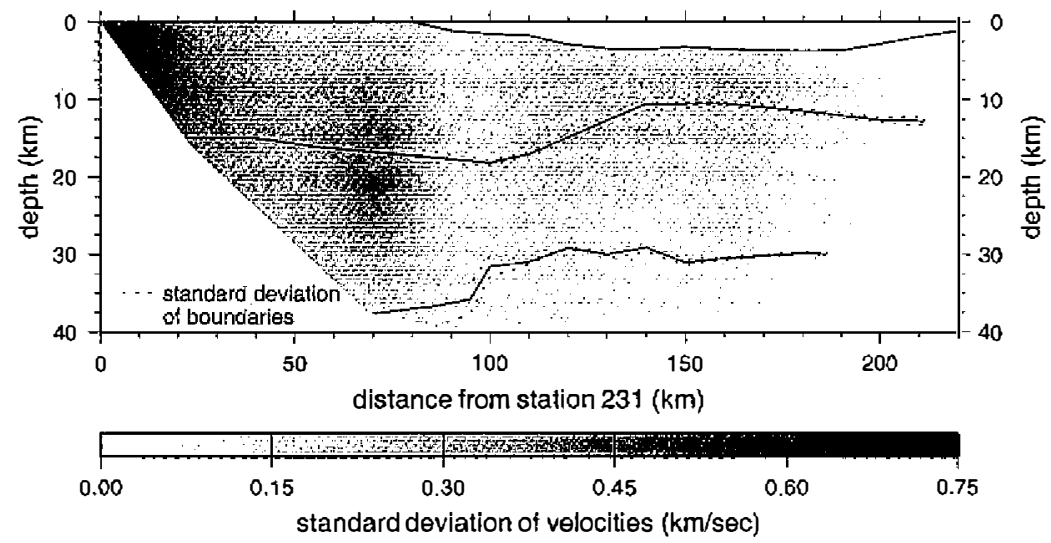

Fig. 8. Model of the northern offshore-onshore profile. a) $\mathrm{P}$ wave velocity in the section of the profile with ray coverage. Dashed contours indicate 0.5 $\mathrm{km} / \mathrm{sec}$ isovelocity contours, and solid black circles indicate points where velocity was parameterized. Velocity is shaded continuously, so discontinuities in the model for ray-tracing are represented as large velocity gradients. Solid lines indicate the mid-crust boundary and the Moho. Topography along the profile is plotted above the section: WF is the Western Foothills; HR is the Hsuehshan Range; BR is the Backbone Range; and ECR is the Eastern Central Range. See Fig. 1 for locations of the cross-sections. b) Standard deviations of the model parameters of all resultant models obtained in this study. See the Discussion section of the main text for further explanation. 


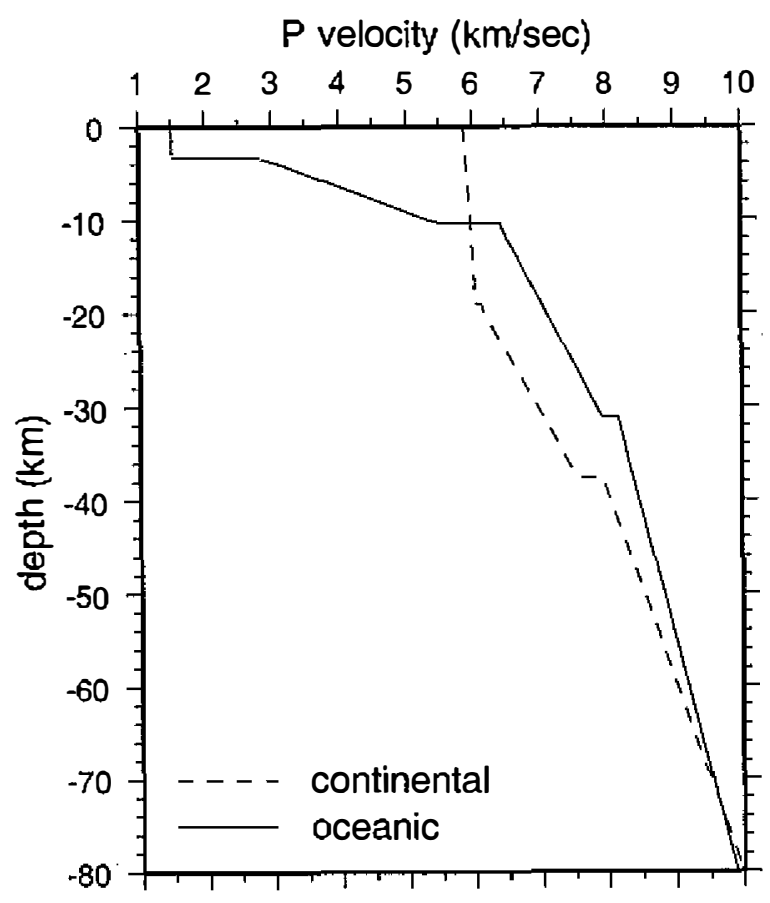

Fig. 9. Two 1-D velocity curves of the presented final model in Figs. $6 \mathrm{a}$ and 8 . One velocity curve is for the oceanic crust $(\mathrm{v}=1.5 \mathrm{~km} / \mathrm{sec}$ at the surface), and the other is for the continental crust.

obtained in this study. First, there is a deviation in the trend of the Moho between about 100-150 $\mathrm{km}$ from the western end of the model (station 231 at the surface; Figs. 6 and 8). Second, the average lower-crust velocity under Taiwan was about $1.5 \mathrm{~km} / \mathrm{sec}$ lower than the average lowercrust velocity under the ocean (Fig. 9). Finally, there was a small velocity discontinuity in the mid-crust under the Eastern Central Range (Fig. 6).

The low velocity zone in the upper-crust offshore Taiwan and the small mid-crust velocity discontinuity beneath Taiwan were needed to describe the observed changes in apparent velocities between the Pg arrivals and the adjacent Pc arrivals (Figs. 3 and 5). Calculated travel-times of Pg, Pc, Pn and mantle-refracted P recorded at station 229 for the preferred model are presented in Fig. 10 along with the travel-time picks from station 229 (for comparison see Fig. 3b).

Another result which was consistent in all resulting models was that the average velocities under the Taiwan orogen were higher in the upper-crust and lower in the lower-crust compared to those in the oceanic crust (Fig. 9). The lateral velocity gradient in the lower-crust partly explains the drastic changes in the apparent velocities of Pg and Pc (Fig. 10). The change in the upper-crust velocities from offshore to onshore can be attributed to the fact that there are thick sedimentary layers on the ocean side of the profile (McIntosh and Nakamura 1998; Wang and Chiang 1998) and high density rocks at shallow depths under the orogen (Wu et al. 1997). The velocities in the lower-crust under the ocean are expected to be high since they represent the dense crust of the subducted PSP and the non-volcanic Ryukyu Arc basement. In contrast, the lower-crust under the orogen consists of less dense material composing the root of the mountains. 


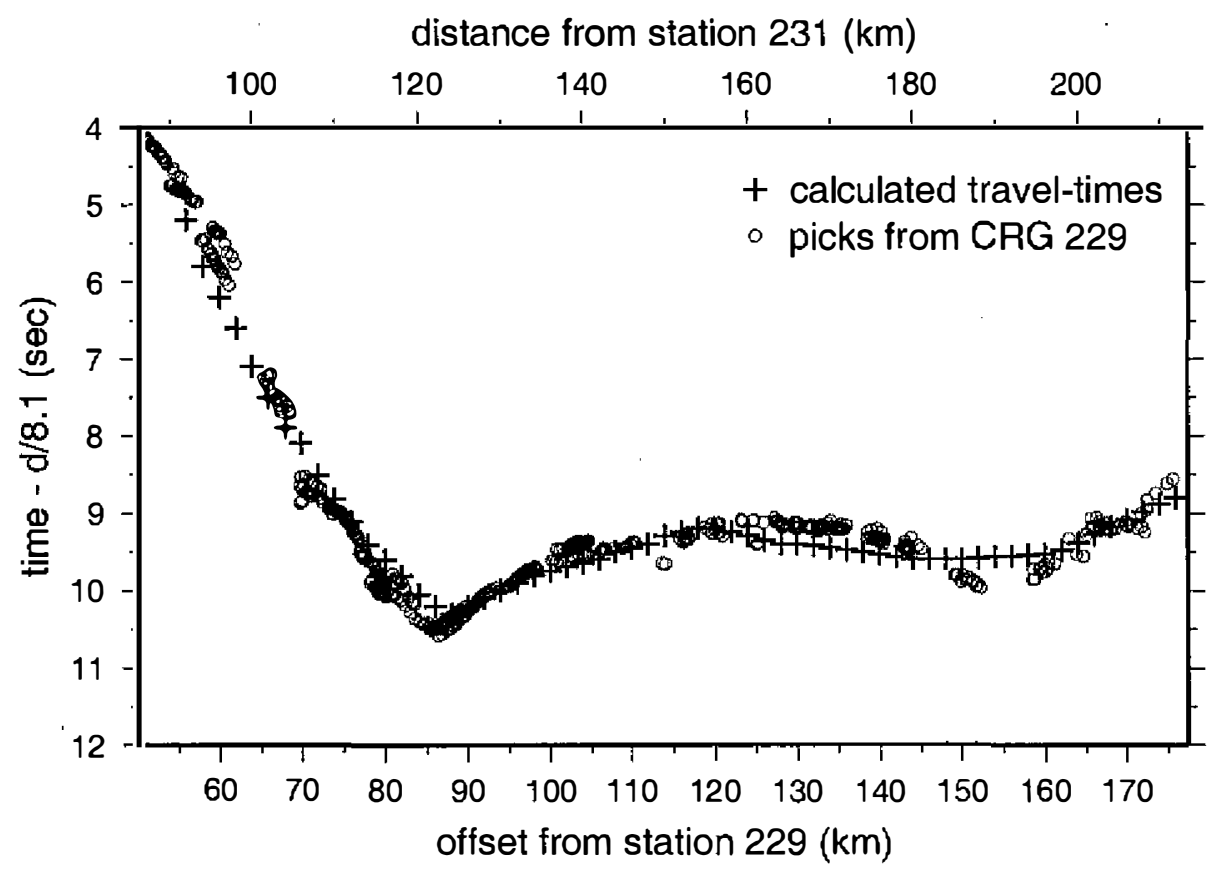

Fig. 10. Calculated travel-times (crosses) of all refracted $\mathrm{P}$ waves compared to the observed travel-times (open circles) in the common receiver gather of station 229.

A structural difference in all of the resulting models was the lateral position where the Moho drastically increased in depth. This can be seen in the high standard deviation of the Moho under the coast of Taiwan (Fig. 8b). The models that had a Moho similar to the one in the presented model were able to describe the data recorded at the four central stations better than those with a Moho that increased in depth east of, rather than beneath, the coast of Taiwan.

In Fig. 11 we compared the model obtained in this study with OBS Line 16 (Wang and Chiang 1998) and the tomography of Rau and Wu (1995). The Moho geometry compares well both with the Moho in the OBS model and with the oceanic mantle velocities indicated in the tomography. Additionally, the model of OBS Line 14 (McIntosh and Nakamura 1998) shows the Moho at depths consistent with the results obtained in this study. Furthermore, the mid-crust velocity discontinuity obtained in these results is also present in the OBS models. High velocities (over $8 \mathrm{~km} / \mathrm{sec}$ ) were resolved at depth under the east coast of Taiwan (Rau and Wu 1995) and were interpreted by $\mathrm{Wu}$ et al. (1997) as indicative of oceanic mantle under the eastern edge of the orogen. The position of the Moho under the coast of Taiwan, determined in this study (Figs. 6 and 8), is consistent with the interpretation of the onshore tomography (Fig. 11). Moreover, the velocities determined in the onshore tomography are consistent with the crustal velocities under the eastem part of Taiwan as determined here (Figs. 8 and 11).

The models of OBS Lines 14 and 16 include a second lower-crust transition, which is attributed to the transition from the top of the PSP to the bottom of the non-volcanic Ryukyu 


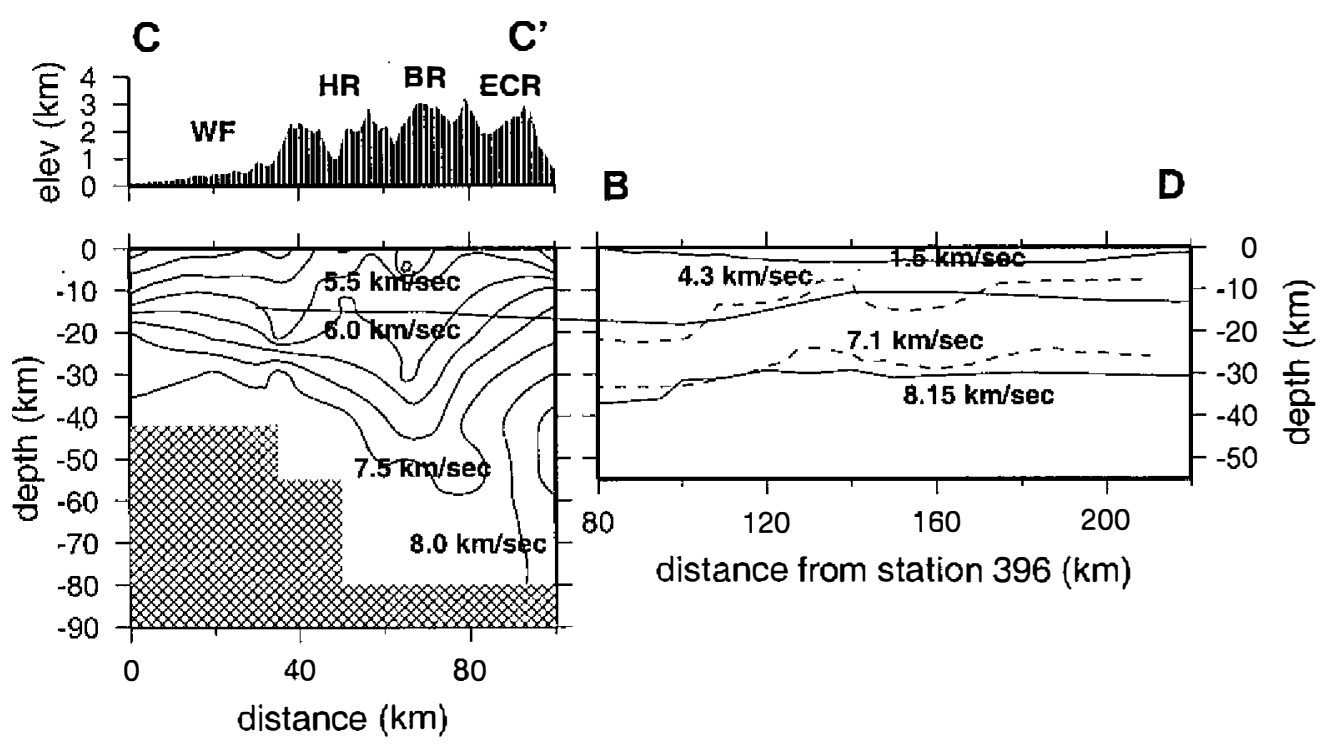

Fig. 11. Comparison of the model determined in this study with the onshore tomography (Rau and Wu 1995) and OBS Line 16 models (Wang and Chiang 1998). Dashed lines are the 6.25 and $7.8 \mathrm{~km} / \mathrm{sec}$ velocity discontinuities from the OBS model. The upper and lower solid lines are the mid-crust velocity discontinuity and the Moho geometry determined in this study. The given velocities in the tomographic cross-section refer to the iso-velocity contours, and given velocities in the offshore section refer to the approximate average velocity in each layer of the offshoreonshore model. Station 231 is located about $25 \mathrm{~km}$ from the origin on the tomographic cross-section. See Fig. 1 for the locations of the cross-sections.

Arc basement (McIntosh and Nakamura 1998); however, the velocity discontinuity is slight and we were unable to image it with these offshore-onshore data. Finally, the low velocity zone in the upper-crust near the coast of Taiwan was also resolved in the OBS models of Lines 14 and 16.

\section{CONCLUSIONS}

We modelled $\mathrm{P}$ wave arrivals recorded by nine onshore recorders from over 1800 air-gun shots of the R/V Maurice Ewing in 1995. The results of the study indicate that the Moho is at about 30-35 km depth below sea level offshore of Taiwan and that it dips slightly westward towards the east coast. That the Moho of the PSP has depressed to over a $30 \mathrm{~km}$ depth is consistent with the model that the PSP is subducting under the EP to the north, and the depth determined here indicates a total depression of about $15 \mathrm{~km}$ due to this subduction.

An immediate question when interpreting these results is whether the transition from oce- 
anic to continental crusts can be determined with these data. It has already been established by tomographic studies that oceanic mantle velocities are as far west as about $121.5 \mathrm{E}$ (approximately $80 \mathrm{~km}$ from station 231; Rau and Wu 1995; Wu et al. 1997). The present offshore-onshore data support this earlier finding, suggesting that the oceanic mantle and the Moho extend under the Eastern Central Range (Fig. 11). However, it was not possible to determine a discrete transition between the oceanic and continental crusts with the data presented here.

The upper-crust low velocity zone near the coast of Taiwan coincides with the large gravity low of up to $-160 \mathrm{mgals}$ offshore Taiwan (Hsu et al. 1998). The low velocity indicates that the Hsincheng Ridge is a sedimentary feature, possibly a result of fluvial deposits from the Longitudinal Valley. Furthermore, there appears to be an extensive, relatively low velocity region in the upper-crust that may extend to mid-crustal depths. This may represent the top of the westernmost structure of the non-volcanic Ryukyu Arc or the northernmost structure of the Luzon Arc, and it is adjacent to the Central Range onshore, which is part of the EP continental crust (Fig. 8). The models of OBS Lines 14 and 16 also indicate a region of relatively low velocity extending to the mid-crust (McIntosh and Nakamura 1998; Wang and Chiang 1998). However, both models have low ray coverage in this area: OBS Line 14 has $0-10 \%$ of the maximal ray coverage in the mid-to-lower crust on the western side of the profile (McIntosh and Nakamura 1998), while OBS Line 16 has $0-15 \%$ ray coverage (Wang and Chiang 1998).

It is worth noting that the Moho of the PSP crust along this profile is relatively undeformed compared with the southern offshore-onshore profile, where it is dramatically depressed towards the island, indicating significant shortening of the PSP as a response to the collision (Hetland and Wu 1998b). If the collision along the northem profile has resulted in significant shortening of the PSP crust, it is not apparent from the deformation of the Moho. The westward dip of the Moho may be a response to shortening, but on the other hand, it may only be an apparent dip, with the maximum Moho dip to the NWN due solely to subduction. This in fact appears to be the case, since the north-south trending OBS profile along Ewing Line 1 indicates that the PSP dips to the north about $25^{\circ}$ in this region (Wang et al. 1996). These results, as well as OBS Lines 14 and 16, indicate the PSP dips about $5^{\circ}$ to the west. This would indicate the maximum dip direction is to the NWN, which is consistent with the plate motion of the PSP relative to the EP.

Acknowledgements We wish to acknowledge the support of NSF grant INT9513945. The field work was carried out with support from the Institute of Earth Sciences, Academia Sinica, under the leadership of Dr. Y. H. Yeh; in paricular, the able group under C. C. Liu lent strong assistance in the field. Dr. R. J. Rau, then at SUNY Binghamton, was responsible for the deployment of our onshore stations. The timely support by the Lamont PASSCAL Instrumentation Center and IRIS/PASSCAL program made the onshore recording possible. The planning of the R/V Ewing cruise by Prof. C. S. Liu of National Taiwan University contributed to the success of the field operation. We also thank Prof. C. S. Lee and the editors of TAO, and one anonymous reviewer, whose keen suggestions and comments greatly improved this manuscript. 


\section{REFERENCES}

Angelier, J., E. Barrier, and H. T. Chu, 1986: Plate collision and paleostress trajectories in a fold-thrust belt: the Foothills of Taiwan. Tectonophysics, 125, 161-178.

Barrier, E., and J. Angelier, 1986: Active collision in eastern Taiwan: the Coastal Range. Tectonophysics, 125, 39-72.

Biq, C. C., 1972: Dual trench structure in the Taiwan-Luzon region. Proc. Geol. Soc. China, 15, 65-75.

Bowin, C., R. S. Lu, C. S. Lee, and H. Schouten, 1978: Plate convergence and accretion in the Taiwan-Luzon region. Am. Assoc. Petrol. Geol. Bull., 62, 1645-1672.

Chai, B. H. T., 1972: Sructure and tectonic evolution of Taiwan. Am. J. Sci., 272, 389-422.

Cohen, J. K., and J. W. Stockwell Jr., 1999: CWP/SU: Seismic Unix Release 33: a free package for seismic research and processing. Center for Wave Phenomena, Colorado School of Mines.

Hetland, E. A., and F. T. Wu, 1998a: Analysis of two offshore-onshore seismic refraction transects in Taiwan: deformation of the crust due to arc-continent collision. EOS, Trans. Am. Geophys. Un., 79 (24), W 113.

Hetland, E. A., and F. T. Wu, 1998b: Deformation of the Philippine Sea Plate under the Coastal Range, Taiwan: results from an offshore-onshore seismic experiment. TAO, 9 , 363-378.

Ho, C. S., 1986: A synthesis of the geological evolution of Taiwan. Tectonophysics, 125, 1-16.

Huchon, P., E. Barrier, J. C. De Bramaecker, and J. Angelier, 1986: Collision and stress trajectories in Taiwan: a finite element model. Tectonophysics, 125, 179-191.

Hsu, S. K., C. S. Liu, et al. 1998: New gravity and magnetic anomaly maps in the Taiwan-Luzon region and their preliminary interpretation. TAO, 9, 509-532.

Katsumata, M., and L. R. Sykes, 1969: Seismicity and tectonics of the western Pacific: Izu-Mariana-Caroline and Ryukyu-Taiwan regions. J. Geophys. Res., 74, 5923-5948.

Lay, T., and T. C. Wallace, 1995: Modern global seismology. Academic Press, 517 pp.

McIntosh, K. D., and Y. Nakamura, 1998: Crustal structure beneath the Nanao forearc basin from TAICRUST MCS/OBS Line 14. TAO, 9, 345-362.

Oppenheim, A. V., and R. W. Schafer, 1989: Discrete-time signal processing. Prentice Hall, $879 \mathrm{pp}$.

PASSCAL Field Manual, 1994: IRIS, Arlington, VA.

Rau, R. J., and F. T. Wu, 1995: Tomographic imaging of lithospheric structures under Taiwan. Earth Planet. Sci. Lett., 133, 517-532.

Shih, R. C., C. H. Lin, et al. 1998: Preliminary crustal structures across central Taiwan from modeling of onshore-offshore wide-angle seismic data. TAO, 9, 317-328.

Wang, T. K., K. McIntosh, Y. Nakamura, and C.S. Liu, 1996: OBS refraction survey and imaging offshore eastern Taiwan. EOS, Trans. Am. Geophys. Un., 77 (46), F731.

Wang, T. K., and C. H. Chiang, 1998: Imaging of arc-arc collision in the Ryukyu forearc 
region offshore Hualien from TAICRUST OBS Line 16. TAO, 9, 329-344.

Wu, F. T., 1978: Recent Tectonics of Taiwan. J. Phys Earth, 26, S265-S299.

Wu, F. T., R. J. Rau, and D. Salzberg, 1997: Taiwan orogeny: thin-skinned or lithospheric collision?. Tectonophysics, 274, 191-220.

Yang, Y. S., and T. K. Wang, 1998: Crustal velocity variation of the western Philippine Sea Plate from TAICRUST OBS/MCS line 23. TAO, 9, 379-394.

Yeh, Y. H., R. C. Shih, et al. 1998: Onshore/offshore wide-angle deep seismic profiling in Taiwan. TAO, 9, 301-316.

Yu, S. B., H.Y. Chen, and L. C. Kuo, 1997: Velocity field of GPS stations in the Taiwan area. Tectonophysics, 274, 41-60.

Zelt, C. A., and R. B. Smith, 1992: Seismic traveltime inversion for 2-D crustal velocity structure. Geophys. J. Int., 108, 16-34. 